\title{
Discussion on the Promotion Strategy of Convenience Store Service
}

\author{
Xinxin Wang ${ }^{1, *}$ \\ ${ }^{1}$ Shandong Institute of Commerce \& Technology, Ji'nan, Shandong 250103, China \\ "Corresponding author. Email: wxxlbz@163.com

\begin{abstract}
Compared to such areas with mature convenience stores as Japan and Taiwan, stores in mainland China enjoy bright prospect in terms of quantity. However, with the popularization of mobile Internet and the fierce competition in retail market, the comparative advantage of convenience stores is wearing thin. This paper analyzes the problems in the service aspect of convenience stores from six aspects of commodity category, commodity information introduction, commodity price, store personnel service,
\end{abstract} \\ store supplementary service and customer feedback, and puts forward countermeasures.
}

Keywords: convenience store, commodity, personnel, service

\section{INTRODUCTION}

The traditional brick-and-mortar retail industry has been hit hard by various new retail forms incurred by the continuous development of Internet technology. The absolute advantage once enjoyed by convenience stores is gradually losing relevance, which requires stores to innovate business strategies in time and improve competitive edges. Yin Ye put forward solutions to the food structure of convenience stores in The Strategic Choice of Traditional Convenience Stores Under the New Retail Background. In There Is Still Room for Convenience Stores in the Era of Online Shopping, Zhou Junsheng analyzed the market development space and chain development mode of convenience stores. He $\mathrm{Ke}$ proposed in To Rise after the Epidemic, Convenience Stores Need to be More Sophisticated that convenience stores should pay attention to the delicacy of products, management and marketing. Based on the research of experts, this paper, from the perspective of customer demand and combining with the consumption habits of most customers, analyzes the shortcomings and improvement strategies of convenience stores from the aspects of the attractiveness of commodity categories and information, store price, image, convenience of service, etc.

\section{THE INTRODUCTION OF CONVENIENCE STORE}

Convenience stores are generally in proximity to residential areas, schools, office areas, or densely populated areas near gas station. They mainly sell ready-to-eat goods, regular food and daily necessities to meet customers' needs with small radiation radius. It is a small retail industry in which customers serve themselves. According to location, convenience stores are divided into traditional convenience stores and gas station convenience stores. This paper mainly studies the traditional community-based convenience stores.

\section{THE DEVELOPMENT ADVANTAGE OF CONVENIENCE STORE INDUSTRY}

\section{A. Policy support}

At the end of 2019, the Ministry of Commerce and 13 other departments jointly issued Guidelines on Accelerating the Development of Brand Chain Convenience Stores (hereinafter referred to as the Guidelines) to promote the development of convenience stores. The Guidelines put forward that the business environment of convenience stores should be optimized, its brand, chain and intelligent development should be promoted, its important role in serving people's livelihood and promoting consumption should be better played, and all localities should be encouraged to make effective use of the space resources of stateowned enterprises and institutions and set up convenient commercial facilities such as brand chain convenience stores. $^{1}$

Zhong Shan, the Minister of Commerce, said at a press conference on May 18, 2020 that the 130,000 convenience stores in China are far from enough to meet people's needs. In the future, the Ministry of Commerce should focus on optimizing the layout and promoting the chain development of convenience

\footnotetext{
How do enterprises view the 18 development policies convenience store ushered in? [Z]. Linkshop http://www.linkshop.com.cn/web/archives/2020/439706.shtml
} 
stores. ${ }^{2}$ Local policies in many big cities have been increasingly supportive to the development of convenience stores. In Beijing, for example, the cap for supporting new outlets such as convenience stores will be raised to $70 \%$ in early 2020 .

\section{B. Market opportunities}

In terms of the saturation of convenience stores, the density of convenience stores in Taiwan, China is the highest in the world. The total number of stores has exceeded 10,000, with one convenience store for every 2,000 people. In mainland China, the number of convenience stores in first-tier cities such as Beijing, Shanghai and Guangzhou tends to be saturated, while stores in other cities still have a large space for development.

\section{ANALYSIS ON THE PROBLEMS EXISTING IN THE SERVICE OF CONVENIENCE STORE INDUSTRY}

\section{A. Products are slow to update and unattractive}

The convenience store industry generally relies on ready-to-eat commodities to attract customers. For example, the world's largest 7-Eleven, known as the "real super species" in the industry, has a very high proportion of ready-to-eat commodities. Although many community-based convenience stores in China also cover ready-to-eat products, they are not attractive to customers due to their poor variety and slow updating speed of individual products.

\section{B. The introduction of the goods is not informative enough}

The popularity of the mobile Internet makes many customers prefer the mode of "ordering online and having them delivered". To meet the changing trend of consumer demand, many retailers have adopted online and offline omni-channel services. Most convenience stores have also established and opened some online sales platforms, including WeChat official account, APP, and cooperation with third-party platforms (such as Jingdong Home, Meituan, Taobao, etc.). However, compared with many e-commerce enterprises, there is still a big gap in commodity information introduction. The commodity introduction of convenience store enterprises is dwarfed by the popular network interaction forms such as short video and live broadcast. The commodity information on the online network platform of convenience stores is poor, with only the most basic static forms such as text and

\footnotetext{
2 Zhong Shan, Minister of Commerce: The number of convenience stores nationwide is not enough [Z]. Linkshop. http://www.linkshop.com.cn/web/archives/2020/447755.shtml?sf=wd _search
}

pictures, and some pages are very low in clarity, so that customers can barely understand the most basic commodity information. Due to the monotonous product introduction information, customers' purchasing desire is not sufficiently stimulated.

\section{Higher commodity prices}

The survey shows that the overall commodity prices of most convenience stores in China are higher than those of some e-commerce enterprises and large supermarkets. Although many convenience stores also offer online ordering and home delivery services, most of them require delivery fees. The commodity prices of convenience stores are higher than those of other retail industries. In the early development of convenience stores, customers may voluntarily pay high prices for the convenience offered. But now that other retailers offer "home delivery" services that are more "convenient" and cheaper than convenience stores, convenience store customers turn to other stores.

\section{The service of personnel is poor}

According to the survey, many traditional convenience store stores have a small number of employees who work as cashiers, tally clerks and information administrators. The store management is not in place, the service attitude, language and actions of store employees cannot be institutionalized and standardized, thus the service of store personnel cannot be guaranteed.

\section{E. Few supplementary services}

In Japan and Taiwan, where convenience stores have developed well, there are many supplementary service items, including life payment, purchase of tickets, free home delivery, delivery of express, printing and copying, taxi hailing, free bathroom, etc., covering all aspects of customers' daily life. 7-Eleven has provided more than 50 types of services, and customers have countless reasons to arrive at convenience stores for shopping. But many convenience stores in China still focus on selling goods, with few additional services.

\section{F. Not paying enough attention to customer feedback}

A lot of convenience store enterprises have contact for customer feedback, but generally it is in name only and the sign of contact is not eye-catching. Convenience stores also do not have enough material incentives to pool feedback. Customers will only respond to and seek compensation for material or other losses caused by shopping in convenience stores. Even if the customer has good suggestions or needs that cannot be met, such as category, single product configuration, etc., they will not actively inform the 
convenience store, but turn to other retailers for satisfaction.

\section{PROMOTION STRATEgIES FOR CONVENIENCE STORE SERVICES}

\section{A. Improving the structure of goods and increasing the frequency of customer purchase}

Convenience store enterprises should keep up with the changing trend of market demand to adjust the commodity structure. 7-Eleven stores in Japan update their offerings very quickly, with about 2,900 items per store, up to $70 \%$ of all items updated in a year. Therefore, it is called "retail manufacturing". Despite many years of operation, 7-Eleven is still regarded as a "young enterprise", which can meet the demands of customers in terms of commodity category and supplementary service. The reason lies in its extreme insight into customer needs. 7-Eleven's focus is not on rivals, but always on customers. Through investigation and study of customer demand, 7-Eleven makes strict selection of individual products and strives to create every flagship product. For example, 7-Eleven successively introduced the bento, buckwheat noodles, coffee and so on. In 7-Eleven, each item in the store is a specific category role. At present, China's convenience store enterprises can improve the commodity structure from the following aspects:

1) Increasing fresh commodities: People cannot live without fresh food for three meals a day, so fresh goods are goods with rigid demands, and customers' purchase frequency is very high. If consumers buy online or buy in the community, the quality of goods is not stable. So many customers like to go to the nearest store and pick them up. Many retail stores, such as supermarkets, regard fresh food as a very important drainage product to boost the popularity of the store, so as to drive the sales of other products in the store. Community-based convenience stores can make full use of the advantage of convenient distance to increase the quantity and proportion of fresh goods in the store, so as to improve the popularity of convenience stores and promote the sales of other daily necessities.

2) Enriching ready-to-eat commodities: With the quickening pace of life, the demand of target customers for instant food commodities in convenience stores is increasing. However, for boxed lunch products, customers pay more attention to the variety and variability of taste. Therefore, convenience store enterprises should not only enrich the types of ready-toeat commodities, but also keep innovating to maintain customer loyalty. 7-Eleven, the world's dominant convenience store, has a long history, which is closely related to its strong product development capability. It has always been committed to developing high valueadded products, constantly creating "delicacies", researching "dishes that are not easy for the family to cook" or "tastes that require more effort to achieve", and constantly launching new products to meet the needs of customers. Some convenience stores in China have started to increase the proportion of ready-to-eat commodities. For example, The $\mathrm{C} \& \mathrm{U}$ in Zhejiang province recently launched 16 kinds of affordable bento, and the order volume has exploded.

3) Increasing the proportion of private-brand goods: Compared with suppliers' brand products, retailers' private brand products are better in quality, lower in price and higher in cost performance due to the absence of middlemen. The technical content of daily necessities is not high, and customers pay more attention to their cost performance. Due to the COVID19 epidemic in 2020, many retailers in China have seen significant growth in the sales of private label goods. Convenience store enterprises should also strengthen the research and development of private brands, and increase the proportion of private brand products in the commodity structure, so as to improve their unfavorable image of high prices in the eyes of consumers.

\section{B. Strengthening the way of commodity information dissemination to stimulate the purchase desire of customers}

In order to adapt to the changing market environment and meet the consumer demand, convenience store enterprises can appropriately add dynamic ways such as video or live broadcast on their online display platform, strengthen interaction, and guide customers for feedback, so as to enrich information, cultivate customers' consumption habits and increase the frequency of purchase. For example, ready-to-eat commodities not only need basic information such as commodity function, ingredients and price, but also need vivid commodity introduction and video demonstration to stimulate customers' appetite and purchase desire. For coffee and other drinks, information about consumption habits should be added to guide customers to make multiple purchases to increase their purchase frequency. Stores should not only provide home delivery service, but also inform target customers of home delivery service through various channels such as store publicity, so as to increase store sales.

\section{Optimizing the supply chain to reduce cost}

Convenience stores should optimize and improve the efficiency of the supply chain to reduce the cost of goods, and finally reduce the selling price of goods. Every link in the 7-Eleven supply chain is carefully designed to improve efficiency and reduce costs. For 
example, 7-Eleven has canceled the "delivery and inspection" in stores early, which greatly saves the delivery time and improves the distribution efficiency.

\section{Improving service to increase customer loyalty}

Convenience store enterprises should standardize all kinds of store services to ensure the quality of store service. In terms of store services of convenience stores, including service language, service attitude, service actions and other personnel services, the headquarters should strengthen the standardization and management, refine various service standards, and strictly supervise the delivery of store service quality through system management, shop tour, etc..

\section{E. Adding service items to increase popularity}

Convenience stores should not only bring customers the convenience of purchasing goods anytime and anywhere, but also provide other convenient services, so that customers can enjoy a full range of convenient services. Japan's 7-Eleven has done its best to make things easier for customers. It has become not just a retail company, but part of the social infrastructure. For example, it took on the role of disaster relief when the earthquake came and provided livelihood security. Chinese convenience stores can improve their service and popularity in the following aspects.

1) Enriching the cultural functions of convenience stores: Many convenience stores have newsstands, but not enough. On the basis of existing resources, convenience stores can add more and newer newspapers, magazines, books and so on to provide free on-site reading, so as to meet the diversified needs of customers and enhance the popularity of stores.

2) Increasing convenience programs: According to the Guidelines, convenience stores can foray into the operation of books and newspapers, printing and copying, withholding and payment, collection and delivery, express storage, elderly housekeeping, waste goods recycling and other services ${ }^{3}$, so that customers can enjoy more convenient services.

3) Providing free delivery service: With the popularization of mobile Internet, many customers are used to the mode of online ordering and home delivery. Especially in early 2020, consumer demand for home business has exploded due to the COVID-19 epidemic. Convenience store enterprises also need to optimize their home delivery, such as eliminating the delivery cost, cooperating with more platforms to make it more convenient for customers to understand and use home

\footnotetext{
How do enterprises view the 18 development policies convenience store ushered in? [Z]. Linkshop http://www.linkshop.com.cn/web/archives/2020/439706.shtml
}

services, enriching the product categories and product introduction information of online sales platforms, opening the mode of all-in-one delivery, widely publicizing and improving sales.

\section{F. Actively listening to customers to meet their needs}

Convenience stores should actively obtain customers' opinions and suggestions, mark clearly the feedback ways of customers' opinions in eye-catching positions in stores and online platforms, and encourage customers to offer feedback actively through material or spiritual incentive, so as to promote stores to timely correct their deficiencies and enhance competitiveness. In terms of receiving customers' complaints and suggestions, convenience store enterprises can learn from the practices of Henan DL Trading Group, which is known as "the best store in China" for its excellent customer service and other aspects. Not only does it set up a customer complaint award of 500 Yuan, but all online and offline platforms mark the way of customer feedback in a prominent position.

\section{CONCLUSION}

In short, the economic and technological environment of the society is constantly changing, as is the competitive environment of businesses. However, the demand of customers for high-quality and low-cost daily consumer goods has not changed, nor has the demand for better and convenient services. Despite fierce competition pressure, as long as convenience store enterprises keep up with the changes in social environment, timely identify the changing trend of consumer demand, adjust business strategy of all aspects, refine store management, improve the efficiency of supply chain, and stick to good goods and services, can they meet consumer demand and achieve long-term sustainable development.

\section{References}

[1] How do enterprises view the 18 development policies convenience store ushered in? [Z]. Linkshop. (in Chinese) http://www.linkshop.com.cn/web/archives/2020/439706.shtml

[2] Zhong Shan, Minister of Commerce: The number of convenience stores nationwide is not enough [Z]. Linkshop. (in Chinese)

http://www.linkshop.com.cn/web/archives/2020/447755.shtml?s $\mathrm{f}=$ wd_search

[3] Yin Ye. The strategic choice of traditional convenience stores under the new retail background [J]. Modern Business, 2020 (2), 22-23. (in Chinese)

[4] Ma Yan, Thoughts, Practices and Strategies of Innovation and Development of Retail Industry in Developing Countries [J]. Journal of Commercial Economics. 2020 (4), 31-34. (in Chinese)

[5] Why 7-11 can get a gross profit of more than 90\% [Z] Linkshop. 
http://www.linkshop.com.cn/web/archives/2017/392225.shtml (in Chinese)

[6] Ge Jinjing, Innovation Research on Traditional Convenience Stores from the Perspective of New Retail [J]. Co-operative Economy \& Science, 2018(01), 74-75. (in Chinese)

[7] Zhang Rui, Problems and Countermeasures in the Chain Store Management Model of Convenience Store [J]. Industrial \& Science Tribune, 2018(06), 238-239. (in Chinese)

[8] Liu Juntong, Discussion on Business Model of Convenience Store Industry - Taking 7-11, Lawson and Quanjia as Examples [J]. Journal of Commercial Economics, 2018(10), 9799. (in Chinese)

[9] Hu Jianbing, Develop Branded Chain Convenience Stores to Meet People's Needs [J]. Guizhou Daily, 2019-07-11 (008). (in Chinese) 